\title{
On the construction of a feasible range of multidimensional poverty under benchmark weight uncertainty
}

\author{
Mehmet Pinar ${ }^{\mathrm{a}}$, Thanasis Stengos ${ }^{\mathrm{b}}$, Nikolas Topaloglou $^{\mathrm{c}, \mathrm{d}}$
}

\begin{abstract}
There are infinitely many alternative benchmark weights that decision makers could choose to measure multidimensional poverty. To overcome the resulting uncertainty, we derive a feasible range of multidimensional poverty that considers all admissible weights within the chosen lower and upper bounds of weights. We use Kenyan and Canadian data to illustrate the use of our methodology, which is an adaptation of existing methods for portfolio analysis based on stochastic dominance. These two-empirical analyses suggest that different weights allocated to poverty dimensions can produce very different multidimensional poverty outcomes for a given population even in cases with small weight perturbations.
\end{abstract}

Keywords: OR in societal problem analysis; Multidimensional poverty measurement; Stochastic Dominance; Mixed Integer Programming

This is the authors' accepted manuscript for the article: Pinar, M., Stengos, T. Topaloglou, N. (2019) "On the construction of a feasible range of multidimensional poverty under benchmark weight uncertainty", European Journal of Operational Research, forthcoming. The final publication is available at: https://doi.org/10.1016/j.ejor.2019.08.047

\footnotetext{
${ }^{a}$ Corresponding author: Business School, Edge Hill University, St Helens Road, Ormskirk, Lancashire L39 4QP, United Kingdom; e-mail: mehmet.pinar@edgehill.ac.uk

${ }^{\mathrm{b}}$ Department of Economics, University of Guelph, N1G 2W1, Guelph, Ontario, Canada; e-mail: tstengos@uoguelph.ca

${ }^{c}$ Ipag Business School, 75006, Paris, France

${ }^{\mathrm{d}}$ Department of International \& European Economic Studies, Athens University of Economics and Business, 76, Patision Street, GR10434, Athens, Greece. Email: nikolas@ aueb.gr
} 


\section{Introduction}

Traditionally the poverty level of a population has been defined in terms of income or wealth alone. However, there is widespread agreement that poverty is a multidimensional concept. For example, the multidimensional poverty index (MPI) of the Oxford Poverty and Human Development Initiative (OPHI) and the United Nations' Development Programme (UNDP) measures poverty in three dimensions (i.e., health, education, and standard of living) and each dimension consists of a different number of indicators.

In this context, there are various judgement calls that need to be made, such as the selection of poverty indicators, deprivation cut-offs for each indicator, weight allocation among the indicators, and so on. In our paper, we focus on the choice of weights given to each poverty indicator. In our paper, rather than pre-determined weighting schemes, we use a data-driven methodology to obtain a feasible range of multidimensional poverty at different multidimensional poverty thresholds (a threshold set to identify multidimensionally poor) by allowing for weights to vary between upper and lower bounds.

The methodology proposed in this paper extends the application of stochastic dominance (SD hereafter) from the one-dimensional case (Atkinson, 1987; Barrett \& Donald, 2003; Davidson \& Duclos, 2000; Duclos, Makdissi \& Wodon, 2005, 2008; Ferre, Ferreira \& Lanjouw, 2012; Foster \& Shorrocks, 1988; Gonzalo \& Olmo, 2014; Linton, Maasoumi \& Whang, 2005; Van de gaer, Vandenbossche \& Figueroa, 2014) to multidimensional poverty analysis.

There has been a recent development of multivariate welfare comparisons with the use of the SD concept. Anderson \& Post (2018) develop SD optimality and inferiority concepts to detect collections of distributions with the highest and lowest levels of shared prosperity, respectively. Anderson, Post and Whang (2019) propose utopia and dystopia indices which can be seen as a generalization of the 'epsilon' index used in almost SD (ASD) to the case of convex SD where more than two incomparable prospects are considered. In the same lines, Maasoumi \& Racine (2016) offer SD conditions of joint multidimensional welfare distributions (e.g., joint distribution of health and income) between different groups (such as different ethnic groups or groups with different educational levels), which corresponds to multidimensional inequality measures proposed by Maasoumi (1986) (see also Bennett, 2010, 2013; Bennett \& Mitra, 2013; Chakravarty \& Zoli, 2012; Duclos, Sahn \& Younger, 2006a, 2006b, 2011; Yalonetzky, 2013).

Neither of the existing literature on multivariate welfare comparisons based on SD examines the potential effect of variation of weights allocated to poverty dimensions on the measured multidimensional poverty levels. Even though the actual welfare distribution does not change with the weight allocation to poverty dimensions, policymakers still choose weights to determine who is multidimensionally poor and also measure multidimensional poverty of a given population. Therefore, the effect of weights on measured multidimensional poverty has relevance for policymakers, something that we aim to investigate in this paper. With an adaptation of the existing methodology for 
portfolio analysis based on SD, we obtain weighting vectors for a given multidimensional poverty threshold that maximizes and minimizes the percentage of a population that have multidimensional poverty above this threshold. This is particularly important as this would allow one to obtain a feasible range of multidimensional poverty above a given threshold, something that would be useful to policymakers as it would allow them to assess the sensitivity of the multidimensional poverty measures to alternative weight choices.

The proposed methodology has also policy implications as it overcomes some of the uncertainties and also provides a more transparent way of measuring multidimensional poverty. In that respect, we provide some discussion on how the proposed methodology helps policymaking.

One of the aims of policymakers is to tackle and eliminate multidimensional poverty with an available given budget. To do that they may choose to prioritise the most deprived regions compared to the least deprived ones. To rank the regions in terms of deprivation (i.e., multidimensional poverty), they first have to make normative decisions to measure multidimensional poverty levels across different regions. Since there are no universally agreed weights on poverty dimensions, policymakers will be tempted to choose a particular set of weights, which would produce multidimensional poverty outcomes that would prioritise areas that are voting for the party that is affiliated with them, a practice very common in developing countries. There is an extensive set of literature that finds that central governments favour core voting areas and punish foes through allocation of resources and investment (see e.g., Cox \& McCubbins, 1986; Diaz-Cayeros, Magaloni \& Estévez, 2016; Dixit \& Londregan, 1996; Golden \& Min, 2013; Livert \& Gainza, 2018; Luca \& Rodríguez-Pose, 2015; Rodríguez-Pose, Psycharis \& Tselios, 2016 among many others). With the use of our proposed methodology some of the ways of manipulating multidimensional poverty levels can be overcome and policymakers could provide more transparent multidimensional poverty levels irrespective of weight choices.

In the next section, we compare our proposed methodology with the existing methodologies that have been traditionally used to obtain alternative weights when examining portfolio efficiency and multidimensional well-being. In section 3, we present the measurement of multidimensional poverty. In Section 4, we outline the proposed methodology that we will use, and we present the mathematical formulation of the proposed methodology in section 5. In Section 6 we present two applications using real-world data from the north-eastern region of Kenya collected from the Kenyan Demographic and Health Survey in 2003 and the Canadian Survey of Labour and Income Dynamics in 2006. Finally, in Section 7 we conclude.

\section{Comparison of proposed methodology with existing methodologies}

In this paper, we obtain a feasible range of multidimensional poverty at a given multidimensional poverty level, which has similar structure as the SD efficiency and super-efficiency 
methodologies that have been used in optimal portfolio construction in finance (e.g., Linton, Post \& Whang, 2014; Scaillet \& Topaloglou, 2010; Post \& Poli, 2016; Arvanitis \& Topaloglou, 2017; Fang \& Post, 2016 ) and multidimensional well-being measurement (e.g., Agliardi, Pinar \& Stengos, 2015; Mehdi, 2019; Pinar, Stengos \& Topaloglou, 2013, 2017; Pinar, Stengos \& Yazgan, 2015). The abovementioned papers use SD efficiency or super-efficiency to obtain single weight allocation to assets in the case of portfolio efficiency or single weight allocation to well-being dimensions in the case of multidimensional well-being measurements. However, obtaining single weighting scheme of poverty dimensions with the use of SD efficiency or super-efficiency, which dominates the multidimensional poverty distribution with benchmark weights at all levels of multidimensional poverty, would not work when measuring multidimensional poverty as this single weighting scheme of poverty dimensions would not offer the poverty-maximizing and -minimizing weights for different multidimensional poverty thresholds.

Another popular method that is used to evaluate a given portfolio's efficiency and construction of composite well-being indices is the nonparametric framework of data envelopment analysis (DEA). The application of the DEA to composite indices is known as the benefit of the doubt (BOD) method, which was first proposed by Kuosmanen \& Post (2001). The construction of these indices is based on the optimization of the arithmetic mean composite indices (see, e.g., Cherchye, Moesen, Rogge \& Van Puyenbroeck, 2007; Cherchye et al., 2008; Athanassoglou, 2016) and optimization of geometric composite indices (see Tofallis, 2013, 2014; Van Puyenbroeck \& Rogge, 2017). Recently, Verbunt \& Rogge (2018) provide an integrated framework that combines optimistic and pessimistic BOD-based weighting schemes. DEA has also been applied for evaluating a given portfolio's efficiency (see, e.g., Chen, Gai \& Gupta, 2018; Lamb \& Tee, 2012; Lim, Oh \& Zhu, 2014, among others). In that respect, Branda \& Kopa (2016) show that the DEA models with the use directional-distance measures (Branda, 2015) are equivalent to the $n$-th order of SD efficiency tests proposed by Post (2003) and Post \& Kopa (2013).

In this paper, unlike SD efficiency (or DEA-like methods) that obtain a single most efficient weighting scheme in portfolio analysis that dominates the market portfolio at all returns, we obtain two sets of weighting vectors that maximize and minimize the proportion of multidimensional poverty that a given population faces at different multidimensional poverty thresholds (i.e., a threshold set to determine multi-dimensionally poor). This is an essential step for multidimensional poverty as multidimensional poverty levels of a given population are obtained by ignoring some parts of the multidimensional poverty distribution (i.e., individuals are considered multi-dimensionally poor if and only if they are deprived above a given threshold). Therefore, we obtain poverty-minimizing and maximizing weights of poverty dimensions for a given multidimensional poverty threshold (i.e., benchmark threshold) rather than obtaining a single weight allocation to poverty dimensions that are based on the whole distribution.

Our application is similar in spirit to the ASD methodology. For instance, Leshno and Levy 
(2002) introduced the ASD concept by limiting the utility functions that are preferred by almost all decision makers, where utility functions do not assign a relatively high marginal utility to very low values or a relatively low marginal utility to large values of returns (see also Bruni, Cesarone, Scozzari \& Tardella, 2017; Lizyayev \& Ruszczynski, 2012). Similar to SD super-efficiency (which looks at the whole distribution of well-being or poverty), ASD super-efficiency also looks at the distribution up to a given point of the distribution. However, the main difference is that the weights obtained may not offer the lowest or highest multidimensional poverty for the points below the chosen cut off point of the distribution. In this paper instead, we obtain weighting vectors that maximize and minimize multidimensional poverty at a given multidimensional threshold with no other alternative admissible weighting schemes offering more (or less) multidimensional poverty than the ones derived.

Another common method that is used in the literature to obtain multidimensional indices is Principal Component Analysis (PCA). Even though PCA is a commonly used methodology in combining multidimensional indices (see e.g., Ogwang \& Abdou, 2003; Singh, Murty, Gupta \& Dikshit, 2012; Smits \& Steendijk, 2015), we did not use the PCA in this paper for two reasons. Firstly, even though the linear combination of components obtained by first principal component explains the highest fraction of the variance in the original variables, it does not say much about the poverty levels obtained with the principal component. Secondly, the first principal component is based on the consideration of the second moment alone after standardizing for a common mean. This would be adequate if the data were characterized solely by the first two moments. However, this is not the case with the poverty analysis in this paper, as we consider the whole distribution of multidimensional poverty up to a given threshold rather than the first two moments.

Other alternative application methods could rely on the use of multi-objective optimization techniques. Such methods are used to solve real-life problems such as electricity provision with poverty considerations (Silva \& Nakata, 2009), agriculture planning (Agrell, Stam \& Fischer, 2004; Sethanan \& Neungmatcha, 2016), forestry management (Palma \& Nelson, 2010), well-being (Brauers, 2008; Omrani, Alizadeh \& Amini, 2019), optimization of forest biomass supply chains (Cambero \& Sowlati, 2014, for a review of different methods in the area), transportation planning (see e.g., Camargo Pérez, Carrillo \& Montoya-Torres, 2015, for review of urban transportation systems), and portfolio management (Fakhar, Mahyarinia \& Zafarini, 2018; Fliege \& Werner, 2013; Xidonas, Mavrotas, Hassapis \& Zopounidis, 2017) among many other areas.

Our approach is closely connected to the concept of minimax robustness first introduced by Soyster (1973) and extensively developed since then (see e.g., Goerigk \& Schöbel (2015) and Ide \& Schöbel (2016) for a detailed review of robust multi-objective minimax optimization methods). Ehrgott, Ide and Schöbel (2014) proposed set-based minimax robust efficiency where the worst case of the objective vector is interpreted as a set, namely the set of efficient solutions to the multiobjective problem of maximizing the objective function over the uncertainty set (see Bokrantz \& Fredriksson, 2017 for necessary and sufficient conditions of Ehrgott, Ide \& Schöbel, 2014). In 
portfolio management for example, the minimax and maximin approaches are used to obtain the different scenarios that minimize the maximum regret (see Xidonas, Mavrotas, Hassapis \& Zopounidis, 2017 for an application) and maximize the minimum returns, respectively. Yet, similar to those of DEA or SD efficiency methods, existing multi-objective methods used for well-being analyses (see e.g., Brauers, 2008; Omrani, Alizadeh \& Amini, 2019) consider maximum and minimum reference points of different attributes. However, multidimensional poverty measurement could depend on a variety of reference points as decision makers could set different thresholds to identify the multi-dimensionally poor, something that we consider in our approach.

In this paper, we extend the methodology of SD super-efficiency tests of Scaillet \& Topaloglou (2010) that generate the set of optimal weights that dominate any other set. Alternatively, the Post (2003) and Kuosmanen (2004) SD efficiency tests generate the set of weights that are not dominated by any other set. Our derivation of the feasible range of multidimensional poverty is based on the Scaillet \& Topaloglou (2010) SD super-efficiency test and as such we obtain the highest and lowest percentage of a population that has multidimensional poverty levels above a given multidimensional poverty level. ${ }^{1}$ Hence, we offer a methodology to obtain feasible ranges of multidimensional poverty at different multidimensional poverty thresholds by imposing a higher and lower "reasonable" set of weights for the poverty dimensions at each threshold. It is expected that most decision-makers (e.g., policymakers) may prefer a "reasonable" weight range for a given dimension (or epsilon deviation from benchmark weights) (see e.g., Foster, McGillivray \& Seth, 2013; Seth \& McGillivray, 2018; Toloo, Sohrabi \& Nalchigar, 2009; Tone \& Tsutsui, 2010 among many others for the discussion of reasonable weights for measuring multidimensional well-being and poverty). Furthermore, imposing lower and upper bounds of weights where dimensional weights could vary is essential to preserve the multidimensional nature of the poverty assessment and avoid corner solutions (i.e., exclusion of some well-being attributes).

\section{Measuring multidimensional poverty}

Obtaining multidimensional poverty measures requires several steps. First, indicator-specific deprivation cut-offs are set to determine whether an individual (household) is deprived or not based on their achievement in each indicator (i.e., indicator-specific deprivation cut-off). Then, each indicator within dimension and dimension is assigned a set of weights representing its relative importance in the overall deprivation to obtain the weighted sum of deprivation of an individual (household). An individual (or a household) is considered as multidimensionally poor if that individual (or household) has a weighted sum of deprivations that is above a cross-dimensional cut-

\footnotetext{
${ }^{1}$ See the Appendix of Arvanitis, Hallam, Post \& Topaloglou (2019) for the discussion that Scaillet \& Topaloglou (2010) derive SD super-efficiency tests rather than SD efficiency tests.
} 
off value. Finally, the overall multidimensional poverty level of a given population is obtained by aggregating all individual poverty levels across the population (see e.g., Alkire \& Foster, 2011 for this class of multidimensional poverty measurement which is a generalization of the Foster-GreerThorbecke (FGT) class of unidimensional poverty measures by Foster, Greer \& Thorbecke, 1984). ${ }^{2}$

We propose a multidimensional poverty measurement that can be used to identify individuals multidimensionally poor if they are deprived in some of the indicators (i.e., intermediate approach). Hence the identification of multidimensionally poor requires a dual cut-off approach. Let us assume that there are $d$ indicators of well-being and $Y_{j}^{i}$ is the achievement level of individual $i$ in indicator $j$. In the first step of the identification, we determine whether an individual (or household) is deprived in indicator $j$ by comparing the achievement in this indicator to the corresponding indicator specific cutoff value $l_{j}$. In the second stage, each indicator is given a weight depending on its importance. Let us consider a $d \times 1$ vector of weights assigned to each indicator, denoted by $\boldsymbol{w}$ which sums to $1 .^{3}$ After defining the weights, an individual is identified as multidimensionally poor if and only if the sum of the weighted deprivations is at least equal to the multidimensional poverty threshold of $k$.

More precisely, let $Y^{i}=\left(Y_{1}^{i}, Y_{2}^{i}, \ldots, Y_{d}^{i}\right)$ denote the achievement vector of an individual $i$ in $d$ indicators. Without loss of generality, the first set of poverty indicators, $0 \leq d_{1} \leq d$ of the random vector $Y^{i}$ to be ordinal and the remaining poverty indicators, $d-d_{1}$ to be cardinal. It should be noted that the cardinal variables (e.g., income, years of schooling) allow one to capture the depth of poverty that a person (population) faces, however, ordinal variables (e.g., self-reported health status, access to electricity) do not capture the depth of poverty except for the headcount ratio, and that none of the FGT-type of multidimensional poverty measures has any meaningful application (see e.g., Allison \& Foster, 299 2004; Foster, Greer \& Thorbecke, 2010 for further discussion on this issue). This has led to different ways of measuring multidimensional poverty when ordinal variables are used in the poverty assessment (see e.g., Alkire \& Foster, 2011; Bossert, Chakravarty \& D’Ambrosio, 2013; Yalonetzky, 2013, 2014; Berenger, 2017 among many others). For a given $0<k \leq 1$ (level of the weighted sum of indicators which identifies the multidimensionally poor), a predetermined $d \times 1$ vector of deprivation cut-offs for each indicator of $\boldsymbol{l} \in(0, \bar{l}]^{d}$, and a $d \times 1$ vector of weights assigned to each indicator $\boldsymbol{w}$, let us provide the poverty measures for a given individual (household) $i$ :

$$
\begin{gathered}
H^{i}(\boldsymbol{l}, k, \boldsymbol{w})=\left[\mathbb{I}\left(\sum_{j=1}^{d} w_{j} \mathbb{I}\left(Y_{j}^{i} \leq l_{j}\right) \geq k\right)\right] \\
P_{\alpha}^{i}(\boldsymbol{l}, k, \alpha, \boldsymbol{w})=\left[H^{i}(\boldsymbol{l}, k, \boldsymbol{w})\left(\sum_{j=1}^{d_{1}} w_{j} \mathbb{I}\left(Y_{j}^{i} \leq l_{j}\right)\right)\right] \\
+\left[H^{i}(\boldsymbol{l}, k, \boldsymbol{w})\left(\sum_{j=d_{1}+1}^{d} w_{j}\left(\frac{l_{j}-Y_{j}^{i}}{l_{j}}\right)^{\alpha} \mathbb{I}\left(Y_{j}^{i} \leq l_{j}\right)\right)\right]
\end{gathered}
$$

\footnotetext{
${ }^{2}$ See Atkinson (2003), Bossert, Chakravarty \& D'Ambrosio (2013) Bossert, D'Ambrosio \& Peragine (2007), Chakravarty and D'Ambrosio (2006), among many others, for measures of multidimensional poverty. ${ }^{3}$ Throughout the paper, we use standardized weights where weights sum to one.
} 
where II is an indicator function taking a value of one if an individual is deprived in the $j$ th indicator (i.e., $Y_{j}^{i} \leq l_{j}$ ), and taking a value of one if an individual is identified as multidimensionally poor when the sum of deprived indicators is at least equal to the multidimensional poverty threshold of $k$ (i.e., $\left.\sum_{j=1}^{d} w_{j} \mathbb{I}\left(Y_{j}^{i} \leq l_{j}\right) \geq k\right)$, respectively. $H^{i}(\boldsymbol{l}, k, \boldsymbol{w})$ in (1a) measures whether individual $i$ is multidimensionally poor or not (i.e. taking a value of one, if the weighted sum of deprivation is at least equal to $k$, and zero otherwise). $P_{\alpha}^{i}(\boldsymbol{l}, k, \alpha, \boldsymbol{w})$ in (1b) ranges between zero and one where the parameter $\alpha$ accounts for the degree to which normalized poverty gaps (or shortfalls) in a given indicator (i.e., $\left(\frac{l_{j}-Y_{j}^{i}}{l_{j}}\right)$ ) are penalized, which is often interpreted as a parameter that measures the level of "poverty aversion". The higher the $\alpha$ the higher the weight given to the shortfalls experienced by the individual (population). $P_{\alpha}^{i}(\boldsymbol{l}, k, \alpha, \boldsymbol{w})$ is the weighted sum of deprivations and weighted normalized poverty gap suffered by individual $i$ when $\alpha=0$ and $\alpha=1$, respectively. The weighted sum of deprivation is the sum of the weights of indicators that a poor individual experiencing deprivation. On the other hand, weighted normalized poverty gap is the sum of the weighted normalized poverty gaps in the indicators that a poor individual experiencing deprivation.

In that respect, the distribution of poverty measures for a given population with $N$ numbers of individuals (or households) can be given by $\boldsymbol{H}(\boldsymbol{l}, k, \boldsymbol{w})$ and $\boldsymbol{P}(\boldsymbol{l}, k, \alpha, \boldsymbol{w})$ as follows:

$$
\begin{aligned}
& \boldsymbol{H}(\boldsymbol{l}, k, \boldsymbol{w})=\left\{H^{i}\right\}_{i=1,2, \ldots, N} \text { for given parameters of } \boldsymbol{l}, k, \boldsymbol{w} \\
& \boldsymbol{P}(\boldsymbol{l}, k, \alpha, \boldsymbol{w})=\left\{P_{\alpha}^{i}\right\}_{i=1,2, \ldots, N} \text { for given parameters of } \boldsymbol{l}, k, \alpha, \boldsymbol{w}
\end{aligned}
$$

$\boldsymbol{H}(\boldsymbol{l}, k, \boldsymbol{w})$ would be a sequence of zeros or ones (whether an individual is multidimensionally poor or not), whereas $\boldsymbol{P}(\boldsymbol{l}, k, \alpha, \boldsymbol{w})$ would range between 0 and 1 (e.g., the weighted sum of deprivations or weighted normalized poverty distributions among multidimensionally poor when $\alpha=0$ and $\alpha=1$, respectively). Given $\boldsymbol{l}, k, \alpha$, and $\boldsymbol{w}$ parameters, the aggregate multidimensional poverty measures for a given population are obtained by averaging the poverty measures as follows (see Bennett \& Mitra, 2013, for generalized measures of Alkire \& Foster, 2011):

$$
\begin{aligned}
& H^{o}=\frac{1}{N} \sum_{i=1}^{N} H^{i}(\boldsymbol{l}, k, \boldsymbol{w}) \\
& P^{o}=\frac{1}{N} \sum_{i=1}^{N} P_{\alpha}^{i}(\boldsymbol{l}, k, \alpha, \boldsymbol{w})
\end{aligned}
$$

Since $H^{i}(\boldsymbol{l}, k, \boldsymbol{w})$ measures whether individual $i$ is multidimensionally poor or not, (3a) measures the overall multidimensional headcount ratio by counting the multidimensionally poor individuals as a proportion of the population. Similarly, $P_{\alpha}^{i}(\boldsymbol{l}, k, \alpha, \boldsymbol{w})$ measures the weighted sum of deprivations and weighted normalized poverty gap suffered by individual $i$ when $\alpha=0$ and $\alpha=1$, respectively and hence, (3b) measures the overall weighted sum of deprivations and weighted normalized poverty gaps that a population experience by averaging the respective multidimensional poverty measures. 


\section{Construction of a feasible range of multidimensional poverty with admissible weights}

Rather than relying on aggregate multidimensional poverty measures for a given population (i.e., an average of poverty measures across individuals), we analyse the cumulative empirical distributions of multidimensional poverty and obtain a feasible range of multidimensional poverty at different multidimensional poverty thresholds with the use of admissible weights.

We will now present some additional notation to build up the proposed methodology. Let us consider a set of the pre-determined $d \times 1$ vector of weights assigned to poverty indicators, $\boldsymbol{w} \in \mathbb{L}$ where $\mathbb{L}:=\left\{\boldsymbol{w} \in \mathbb{R}_{+}^{d}: \boldsymbol{e}^{\prime} \boldsymbol{w}=1\right\}$ with $\boldsymbol{e}$ being a vector of ones where the weighting vector is allowed to range between lower and upper bound of weights (i.e., $w^{L}$ and $w^{U}$, respectively). For a given multidimensional poverty level of $p$ (which could be either weighted sum of deprivations or normalized poverty gap depending on the choice of $l, k$, and $\alpha$ parameters), let us denote cumulative distribution function (cdf) of multidimensional poverty measure as $G(\boldsymbol{l}, k, \alpha, \boldsymbol{w} ; p)$ where the cdfs would change depending on the choice of dimensional weights.

Our methodology aims at obtaining dimensional weights that maximizes and minimizes the cdfs given the parameters: $k$ (i.e. cross-dimensional poverty cut-off), $\boldsymbol{l}$ (i.e. indicator-specific deprivation cut-offs), and $\alpha$ (i.e. poverty aversion parameter).

The empirical counterpart of cdfs of multidimensional poverty measures with any admissible weighting vector $\boldsymbol{w}$ is simply obtained by integrating the empirical distribution $\widehat{G}$ for $G$, which yields:

$$
\widehat{G}(\boldsymbol{l}, k, \alpha, \boldsymbol{w} ; p)=\frac{1}{N} \sum_{i=1}^{N} \mathbb{I}\left(P_{\alpha, \boldsymbol{w}}^{i} \leq p\right)
$$

where $P_{\alpha, \boldsymbol{w}}^{i}$ represent individual $i$ 's multidimensional poverty level with $\boldsymbol{w}$ given $\boldsymbol{l}, k$ and $\alpha$ parameters.

We derive the weighting vectors that maximize and minimize the multidimensional poverty level that a population faces by minimizing and maximizing the cdfs of multidimensional poverty measures up to a given multidimensional poverty level $p$ as follows:

$$
\begin{aligned}
& \min _{\boldsymbol{w}}[\widehat{G}(\boldsymbol{l}, k, \alpha, \boldsymbol{w} ; p)] \text { for a given } p \text { level s.t. } w^{L} \leq \boldsymbol{w} \leq w^{U} \\
& \max _{\boldsymbol{w}}[\hat{G}(\boldsymbol{l}, k, \alpha, \boldsymbol{w} ; p)] \text { for a given } p \text { level s.t. } w^{L} \leq \boldsymbol{w} \leq w^{U}
\end{aligned}
$$

where alternative weights vary between lower bound weights (i.e., $w^{L}$ ) and upper bound weights (i.e., $w^{U}$ ) to include all poverty dimensions in the multidimensional poverty assessment. ${ }^{4}$

As highlighted by the previous literature (see e.g., Anderson, 1996; Anderson \& Post, 2018;

\footnotetext{
${ }^{4}$ As there is no universally agreed benchmark weights, we impose upper and lower bound weights where the benchmark weights could be any weighting vector that lies between these two bounds. Hence, in this paper, we do not impose any benchmark weight, however, in practice policymakers give pre-determined weights to poverty dimensions and the proposed methodology could also be used in the presence of such benchmark weights.
} 
Barrett \& Donald, 2003; Linton, Maasoumi \& Whang, 2005; among many others), in order to account for sampling variation, we will conduct statistical inference with the use of block bootstrapping techniques to test for the significance of the poverty-maximizing and -minimizing weights.

The distribution sets that minimize and maximize $G(\boldsymbol{l}, k, \alpha, \boldsymbol{w} ; p)$ up to a given multidimensional poverty level of $p$ suggest that the proportion of individuals (households) with multidimensional poverty above given multidimensional poverty is maximized and minimized, respectively. Therefore, we use lower and upper bounds of weights for poverty dimensions that maximize and minimize multidimensional poverty at a given threshold, something that results to exact first-order dominance relationship as these bounds also include any other $\boldsymbol{w}$ that lies between these upper and lower bounds. Hence, the weights that maximize and minimize multidimensional poverty (obtained by construction) define what $w^{L}$ and what $w^{U}$ are. In that sense the cdf's at $w^{L}$ and what $w^{U}$ envelops all the other cdf's in between for all the other $w$ that lie between $w^{L}$ and $w^{U}$.

To illustrate how minimization and maximization of cdfs with the admissible weights produce a feasible range of multidimensional poverty at a given multidimensional poverty threshold (i.e., multidimensional poverty level $p$ ), Fig. 1 shows the cdfs of multidimensional poverty obtained with the minimization and maximization of cdfs (i.e., $\min G(\boldsymbol{l}, k, \alpha, \boldsymbol{w} ; p)$ and $\max G(\boldsymbol{l}, k, \alpha, \boldsymbol{w} ; p)$, respectively). For instance, if policymakers set the multidimensional poverty level to 0.5 , they can be confident that the percentage of multidimensional poverty that this population faces ranges between 40 and 60 irrespective of the weight allocations across different poverty dimensions. Given that alternative normative decisions may lead to different policy implications, by deriving a feasible range of multidimensional poverty with the optimization problems, policymakers can be also aware of the effect of alternative weight choices on the multidimensional poverty outcomes, which may also overcome potential manipulation of multidimensional poverty levels with the choice of weights of poverty indicators. ${ }^{5}$

In this paper, we only look at the cdfs of multidimensional poverty, however, if two cdf curves intersect (i.e., $\min G(\boldsymbol{l}, k, \alpha, \boldsymbol{w} ; p)$ and $\max G(\boldsymbol{l}, k, \alpha, \boldsymbol{w} ; p)$ intersect), one can move to integrals of the cdfs (i.e., higher-order of dominance) ${ }^{6}$

\footnotetext{
${ }^{5}$ It should be noted that the poverty-maximizing and -minimizing weights are obtained for a given multidimensional poverty level $p$ and may differ at different $p$ levels. As mentioned before, a single weighting scheme that dominates the whole multidimensional poverty distribution with benchmark weights may not offer the poverty-maximizing or -minimizing case for given multidimensional poverty level. Hence, we obtain poverty-maximizing and -minimizing weights for different multidimensional poverty levels.

${ }^{6}$ The above cases can be easily generalized for the integral of cdfs, however, since we obtain feasible range of multidimensional poverty with admissible weights, we only consider cdfs as the first-order of dominance is less restrictive. For the higher-order of dominance, see for example, Aaberge \& Brandolini (2015) and Aaberge, Peluso \& Sigstad (2015). The above-mentioned papers discuss the desirability of the transfer axiom since transfers from rich to poor makes the distribution of the poverty (well-being) less unequal, hence the distribution with the transfers (or after the progressive tax) second-order dominates the poverty (well-being) distribution without the transfers. In that respect, second-order dominance analysis with multidimensional case is an extension of the generalized Lorenz curve analysis for income distribution offered by Shorrocks \& Foster (1987).
} 


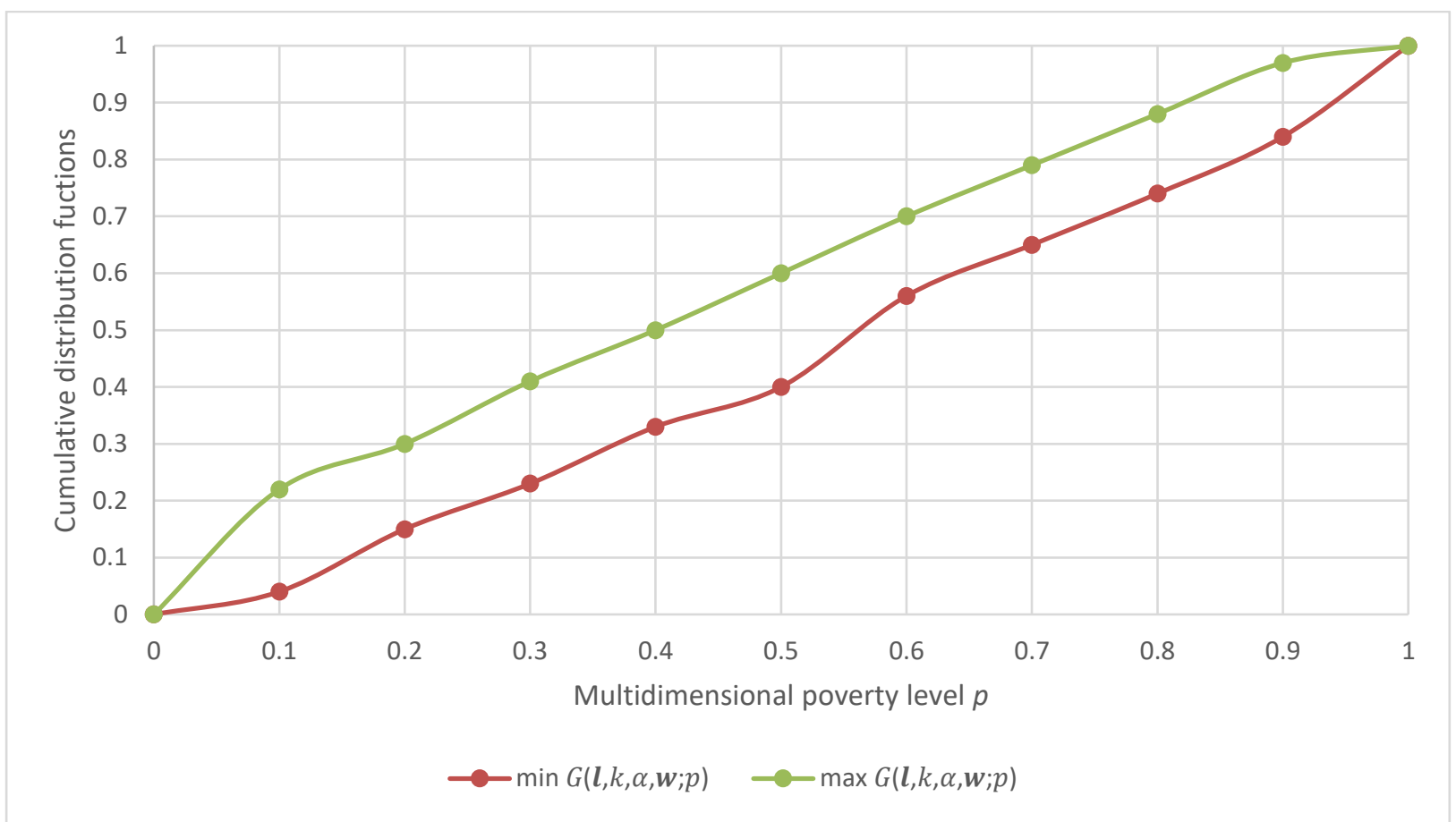

Fig.1. Feasible range of multidimensional poverty with the admissible weights

In the next section, we present the mixed integer programming optimization problem that is used to obtain the weighting schemes that offer the highest multidimensional poverty at a given $p$. Clearly, the derivation of the poverty-minimizing case is analogous (in reverse), and therefore, in the remaining parts of the methodology, we provide the derivation of the poverty-maximizing case to conserve space.

\section{Mathematical formulation of the maximization problem}

The weighting scheme that leads to highest multidimensional poverty above a given multidimensional poverty level of $p$ is obtained by considering all possible weighting schemes that range between upper and lower bounds of dimensional weights through a minimization problem where we use a mixed integer programming to obtain these weighting schemes based on the constraints below:

$$
\begin{array}{ll} 
& \min _{\boldsymbol{w}} \frac{1}{N} \sum_{i=1}^{i=N} W_{i} \text { for a given p level } \\
\text { s.t. } & M\left(W_{i}-1\right) \leq p-P_{\alpha, \boldsymbol{w}}^{i} \leq M W_{i}, \forall i \\
& \boldsymbol{e}^{\prime} \boldsymbol{w}=1 \\
& \boldsymbol{w}>0 \\
& w^{L} \leq \boldsymbol{w} \leq w^{U} \\
& W_{i} \in\{0,1\} \forall i
\end{array}
$$


with $M$ being a large constant.

The model is a mixed-integer program that minimizes the sum over all scenarios of binary variable, $\frac{1}{N} \sum_{i=1}^{N} W_{i}$ which represents $\widehat{G}(\boldsymbol{l}, k, \alpha, \boldsymbol{w} ; p)$ (empirical cdf of multidimensional poverty with the admissible weights, $\boldsymbol{w}$, at a given multidimensional poverty level of $p$ ) According to inequalities (6b), $W_{i}$ equals to one for each scenario $i \in N$ for which $p \geq P_{\alpha, w}^{i}$, and 0 otherwise. In other words, $W_{i}$ equals to one if a given individual $i$ has multidimensional poverty with $\boldsymbol{w}$ that is less than or equal to the multidimensional poverty level of $p$, and zero otherwise. Equation (6c) suggests that the sum of weights given to all poverty indicators to be unity, while inequality (6d) suggests that poverty indicators could get only positive weights. Finally, (6e) suggests that the dimensional weights can only range between lower bound weight $\left(w^{L}\right)$ and upper bound weight $\left(w^{U}\right)$ based on the literature that suggested "reasonable" weight variation among dimensions that disallows corner solutions. The above minimization formulation allows one to obtain weighting scheme that maximizes the number of individuals experiencing multidimensional poverty above a given multidimensional poverty level $p$ with any linear combination of poverty indicators that are ranging between lower and upper bounds of weights.

This minimization problem finds the weighting scheme of poverty indicators, which would result in the lowest possible number of individuals (households) that experience multidimensional poverty levels below or equal to a given $p$ value, which obviously provides the highest number of individuals (households) that experience multidimensional poverty levels that are above a given $p$ value.

The problems above are optimized with the GUROBI solver of the General Algebraic Modelling System (GAMS) software package. All alternative weighting schemes across poverty indicators that are between lower and upper bounds are considered at different multidimensional poverty levels and hence, the problem-solving time increases with the multidimensional poverty levels that one wants to obtain solutions to. In the empirical section, we only present the solutions for some multidimensional poverty levels ranging between 0 and 1 (i.e., poverty-maximizing and minimizing weights at different $p$ levels), however, one can obtain solutions to any multidimensional poverty level that ranges between 0 and 1 .

\section{Empirical Analysis}

In this section, we will apply the above methodology to the real-world data from the northeastern region of Kenya collected from the Kenyan Demographic and Health Survey in 2003 and the Canadian Survey of Labour and Income Dynamics in 2006. With the Kenyan data, we examine whether the multidimensional poverty headcount ratio obtained with the pre-determined weight 
allocation to the dimensions leads to the highest and/or lowest numbers of households that are identified as multidimensionally poor at different cross-dimensional poverty thresholds. ${ }^{7}$ In other words, in the Kenyan case, we set the $\alpha$ parameter to zero and use the same indicator-specific deprivation cut-offs (i.e. $l$ ) and obtain the weighting schemes of poverty dimensions (i.e., health, education, and standard of living) that would lead to lowest and highest number of multidimensionally poor at different cross-dimensional multidimensional poverty cut-off (i.e., $k$ ) levels. On the other hand, with the Canadian data, given the deprivation cut-off lines in each indicator (i.e., $l$ ), we will examine the distribution of the weighted normalized poverty gaps and obtain poverty-maximizing and -minimizing weights at different weighted normalized poverty gaps.

\subsection{Multidimensional poverty in Kenya}

We analyse the multidimensional poverty in the northeast region of Kenya. The data set we use comes from the Demographic and Health Survey of 2003, which was carried out by Central Bureau of Statistics (CBS) in partnership with the Ministry of Health (MOH) of Kenya and the National Council for Population and Development (Central Bureau of Statistics (CBS) [Kenya], Ministry of Health (MOH) [Kenya], ORC Macro, 2004). The sample analysed consists of 2353 individuals and the multidimensional poverty is investigated at the household level and considers three dimensions namely health, education and standard of living, which consist two, two and six indicators to measure deprivation in each respective dimension, respectively. Table 1 presents the dimensions, indicators, deprivation criteria for each indicator and the percentage of individuals that are deprived in each indicator. This table suggests that the individuals in this region are mainly deprived in the standard of living indicators followed by deprivation in indicators of education, while the deprivation levels in health-related factors are relatively lower compared to other two dimensions.

Even though Table 1 presents a general picture on deprivations in the respective indicators, multidimensional poverty headcount of this population is determined after assigning weights to the respective indicators and dimensions, and setting a cross-dimensional multidimensional poverty cutoff value (i.e., weighted sum of deprivation levels) to determine whether a given individual is

\footnotetext{
${ }^{7}$ Alkire, Roche, Santos \& Seth (2011) analyse how country poverty rankings change when alternative weights are used for health, education and standard of living dimensions. Similarly, Alkire \& Santos (2014) analyse whether different cross-dimensional cut-offs affect the poverty rankings of countries. However, above mentioned papers do not analyse how alternative weighting schemes affect the identification of multidimensionally poor at different cross-dimensional cut-offs (i.e., k), which our paper does. In other words, our concern in this paper is not the poverty rankings of the countries but how the identification of multidimensionally poor is affected (to two extreme ends) with different weighting schemes given to the dimensions.
} 


\begin{tabular}{|c|c|c|c|c|c|}
\hline Dimension & Indicator & Deprivation criteria & $\begin{array}{l}\text { Benchmark } \\
\text { weights } \\
\text { within } \\
\text { dimensions }\end{array}$ & $\begin{array}{l}\text { Benchmark } \\
\text { dimensional } \\
\text { weights }\end{array}$ & $\begin{array}{c}\% \text { of } \\
\text { individuals } \\
\text { deprived }\end{array}$ \\
\hline \multirow[t]{2}{*}{ Health } & Nutrition & $\begin{array}{l}\text { A household is considered to be deprived in } \\
\text { nutrition if at least one of its members is } \\
\text { malnourished. Adults are considered } \\
\text { malnourished if their body mass index (BMI) is } \\
\text { below } 18.5 \text { and children are considered } \\
\text { malnourished if their z-score of weight-for-age } \\
\text { is below minus two standard deviations from } \\
\text { the median of the reference population. }\end{array}$ & $1 / 2$ & \multirow[t]{2}{*}{$1 / 3$} & 44.5 \\
\hline & $\begin{array}{l}\text { Child } \\
\text { mortality }\end{array}$ & $\begin{array}{l}\text { A household is considered to be deprived in the } \\
\text { mortality indicator if that household } \\
\text { experienced a child death in the family. }\end{array}$ & $1 / 2$ & & 38.7 \\
\hline \multirow[t]{2}{*}{ Education } & $\begin{array}{l}\text { Years of } \\
\text { schooling }\end{array}$ & $\begin{array}{l}\text { A household is considered to be deprived in the } \\
\text { years of schooling indicator if there is no } \\
\text { household member who has completed five } \\
\text { years of schooling. }\end{array}$ & $1 / 2$ & \multirow[t]{2}{*}{$1 / 3$} & 64.6 \\
\hline & $\begin{array}{l}\text { School } \\
\text { attendance }\end{array}$ & $\begin{array}{l}\text { A household is deprived in the child enrolment } \\
\text { indicator if a school aged child is not attending } \\
\text { school in years } 1 \text { to } 8 \text {. }\end{array}$ & $1 / 2$ & & 67.8 \\
\hline \multirow{6}{*}{$\begin{array}{l}\text { Standard } \\
\text { of living }\end{array}$} & Electricity & $\begin{array}{l}\text { Household is deprived in this indicator if the } \\
\text { household has no access to electricity. }\end{array}$ & $1 / 6$ & \multirow{6}{*}{$1 / 3$} & 94.1 \\
\hline & Sanitation & $\begin{array}{l}\text { Household is deprived in this indicator if the } \\
\text { household's sanitation is not improved or it is } \\
\text { improved but shared with other households }\end{array}$ & $1 / 6$ & & 98.1 \\
\hline & $\begin{array}{l}\text { Drinking } \\
\text { water }\end{array}$ & $\begin{array}{l}\text { Household is deprived in this indicator if the } \\
\text { household does not have any access to clean } \\
\text { water or clean water is more than } 30 \mathrm{~min} \\
\text { walking from home }\end{array}$ & $1 / 6$ & & 90.1 \\
\hline & Flooring & $\begin{array}{l}\text { Household is deprived in this indicator if the } \\
\text { household's main floor has dirt, sand or dung }\end{array}$ & $1 / 6$ & & 89.8 \\
\hline & $\begin{array}{l}\text { Cooking } \\
\text { fuel }\end{array}$ & $\begin{array}{l}\text { Household is deprived in this indicator if the } \\
\text { household cooks with dung, wood or charcoal }\end{array}$ & $1 / 6$ & & 99.9 \\
\hline & Assets & $\begin{array}{l}\text { Household is deprived in this indicator if the } \\
\text { household does not own more than one of the } \\
\text { following items: radio, TV, telephone, bike, or } \\
\text { motorbike, and does not own a car or tractor }\end{array}$ & $1 / 6$ & & 96.6 \\
\hline
\end{tabular}

considered as multidimensionally poor or not. In the benchmark scenario, each indicator within a given dimension, and each dimension is equally weighted (i.e., indicators in health and education dimensions are weighted $1 / 2$, and each indicator in the standard of living dimension is weighted 1/6).

Based on these benchmark weights within dimensions and dimensional weights, one can obtain weighted deprivations in health, education, and standard of living dimensions, and the 
weighted sum of deprivations for each individual. Finally, a cross-dimensional cut-off value (i.e., level of the weighted sum of deprivations) is set to obtain the number of individuals that have a weighted sum of deprivation above this threshold, which is the number of individuals that are multidimensionally poor ${ }^{8}$.

Given that each dimension (health, education, and standard of living) gets the same weight (i.e., 1/3), the number of individuals that have a weighted sum of deprivation above a given crossdimensional poverty cut-off $k$ is known. Hence, we use minimization (maximization) problems set in (4) and (5) to obtain the poverty-maximizing (poverty-minimizing) weighting schemes across the three dimensions for a given cross-dimensional poverty cut-off $k$ that maximize (minimize) the number of individuals that have weighted deprivations above this threshold. Furthermore, given that these three dimensions are important to evaluate multidimensional poverty, we also impose upper and lower bound weights for the three dimensions by setting three sets of lower and upper bound weights as follows: $w^{L}=0.1$ and $w^{U}=0.8 ; w^{L}=0.15$ and $w^{U}=0.70 ; w^{L}=0.2$ and $w^{U}=0.5$.

Panels $\mathrm{A}, \mathrm{B}$, and $\mathrm{C}$ of Table 2 show the poverty-maximizing and minimizing dimensional weights at the different weighted sum of deprivation level (i.e., $k$ level) when given the lower and upper bound weights for dimensions (i.e., $w^{L}=0.1$ and $w^{U}=0.8, w^{L}=0.15$ and $w^{U}=0.70, w^{L}=$ 0.2 and $w^{U}=0.5$ ), respectively ${ }^{9}$. Table 2 also reports the p-values obtained for the significance of weights offered at different multidimensional poverty thresholds based on the block bootstrapping results where we set the block size to 12 and replication number of bootstrapping to 300 . We find that the poverty-maximizing and -minimizing weights obtained at different multidimensional poverty thresholds are all significant at all multidimensional poverty thresholds at the $10 \%$ level with the exception when $k=0.9$ and $w^{L}=0.2$ and $w^{U}=0.5$. Overall, we find that up to the weighted sum of deprivation of 0.8 , there is always an alternative weight that leads to higher and lower multidimensional headcount ratio irrespective of the upper and lower bounds of weights and that standard of living (health) dimensions contribute relatively more towards to the poverty-maximizing (poverty-minimizing) weights. When $k$ is set to 0.9 , weighting health, education and standard of living dimensions $0.15,0.15$ and 0.7 , respectively, produces the highest percentage of multidimensionally poor when $w^{L}=0.1$ and $w^{U}=0.8, w^{L}=0.15$ and $w^{U}=0.70$. On the other hand, if one were to increase the weights of health and education by 0.05 and decrease the weight of standard of living by 0.1 (i.e., if one were to allocate health, education, and standard of living weights of $0.2,0.2$, and 0.6 ,

\footnotetext{
${ }^{8}$ Note that in this application, to obtain a multidimensional poverty measure for a given individual, we keep the deprivation cut-offs for each indicator the same (i.e. $l$ vector is kept the same or deprivation criteria for each indicator is kept the same) and $\alpha$ parameter is set to zero, which gives us the weighted sum of deprivations that each individual faces.

${ }^{9}$ We provide our results for each $k$ that ranges between 0.1 and 0.9 with 0.1 increments; however, povertymaximizing and -minimizing weights could also be obtained for any $\mathrm{k}$ level.
} 
respectively), this weight allocation produces the lowest number of multidimensionally poor when $k$ is set to 0.9 with $w^{L}=0.1$ and $w^{U}=0.8, w^{L}=0.15$ and $w^{U}=0.70$. Finally, when $k$ is set to 0.9 , we find no alternative weighting scheme when the dimensional weights range between 0.2 and 0.5 that produces any different multidimensional poverty headcount ratio.

\begin{tabular}{|c|c|c|c|c|c|c|c|c|}
\hline \multicolumn{9}{|c|}{$\begin{array}{l}\text { Table 2. Poverty-maximizing and -minimizing weights at different multidimensional p } \\
\text { measuring multidimensional poverty in the northeast region of Kenya } \\
\text { Panel A. Poverty-maximizing and -minimizing weights when } w^{L}=0.1 \text { and } w^{U}=0.8\end{array}$} \\
\hline \multirow[b]{2}{*}{$\begin{array}{l}\text { Weighted sum of } \\
\text { deprivation }(k)\end{array}$} & \multicolumn{4}{|c|}{ Poverty-maximizing weights } & \multicolumn{4}{|c|}{ Poverty-minimizing weights } \\
\hline & Health & Education & $\begin{array}{l}\text { Standard } \\
\text { of living }\end{array}$ & $\mathrm{p}$-value & Health & Education & $\begin{array}{l}\text { Standard } \\
\text { of living }\end{array}$ & $\mathrm{p}$-value \\
\hline 0.10 & 0.15 & 0.15 & 0.70 & 0.017 & 0.80 & 0.10 & 0.10 & 0.013 \\
\hline 0.20 & 0.30 & 0.20 & 0.50 & 0.037 & 0.80 & 0.10 & 0.10 & 0.053 \\
\hline 0.30 & 0.15 & 0.15 & 0.70 & 0.010 & 0.70 & 0.15 & 0.15 & 0.027 \\
\hline 0.40 & 0.15 & 0.15 & 0.70 & 0.043 & 0.60 & 0.30 & 0.10 & 0.050 \\
\hline 0.50 & 0.12 & 0.10 & 0.78 & 0.003 & 0.50 & 0.25 & 0.25 & 0.013 \\
\hline 0.60 & 0.12 & 0.10 & 0.78 & 0.047 & 0.80 & 0.10 & 0.10 & 0.027 \\
\hline 0.70 & 0.10 & 0.10 & 0.80 & 0.053 & 0.60 & 0.30 & 0.10 & 0.040 \\
\hline 0.80 & 0.10 & 0.10 & 0.80 & 0.050 & 0.40 & 0.40 & 0.20 & 0.047 \\
\hline 0.90 & 0.15 & 0.15 & 0.70 & 0.053 & 0.20 & 0.20 & 0.60 & 0.050 \\
\hline \multicolumn{9}{|c|}{ Panel B. Poverty-maximizing and -minimizing weights when $w^{L}=0.15$ and $w^{U}=0.7$} \\
\hline \multirow[b]{2}{*}{$\begin{array}{r}\text { Weighted sum of } \\
\text { deprivation }(\mathrm{k})\end{array}$} & \multicolumn{4}{|c|}{ Poverty-maximizing weights } & \multicolumn{4}{|c|}{ Poverty-minimizing weights } \\
\hline & Health & Education & $\begin{array}{l}\text { Standard } \\
\text { of living }\end{array}$ & p-value & Health & Education & $\begin{array}{l}\text { Standard } \\
\text { of living }\end{array}$ & p-value \\
\hline 0.10 & 0.15 & 0.15 & 0.70 & 0.057 & 0.70 & 0.15 & 0.15 & 0.037 \\
\hline 0.20 & 0.30 & 0.20 & 0.50 & 0.023 & 0.70 & 0.15 & 0.15 & 0.040 \\
\hline 0.30 & 0.15 & 0.15 & 0.70 & 0.037 & 0.70 & 0.15 & 0.15 & 0.043 \\
\hline 0.40 & 0.15 & 0.15 & 0.70 & 0.027 & 0.60 & 0.25 & 0.15 & 0.033 \\
\hline 0.50 & 0.20 & 0.15 & 0.65 & 0.007 & 0.50 & 0.25 & 0.25 & 0.037 \\
\hline 0.60 & 0.20 & 0.15 & 0.65 & 0.053 & 0.40 & 0.40 & 0.20 & 0.047 \\
\hline 0.70 & 0.15 & 0.15 & 0.70 & 0.010 & 0.60 & 0.25 & 0.15 & 0.057 \\
\hline 0.80 & 0.15 & 0.15 & 0.70 & 0.047 & 0.40 & 0.40 & 0.20 & 0.037 \\
\hline 0.90 & 0.15 & 0.15 & 0.70 & 0.057 & 0.20 & 0.20 & 0.60 & 0.030 \\
\hline
\end{tabular}

Panel C. Poverty-maximizing and -minimizing weights when $w^{L}=0.2$ and $w^{U}=0.5$

\begin{tabular}{|c|c|c|c|c|c|c|c|c|}
\hline \multirow{2}{*}{$\begin{array}{l}\text { Weighted sum of } \\
\text { deprivation (k) }\end{array}$} & \multicolumn{4}{|c|}{ Poverty-maximizing weights } & \multicolumn{4}{c|}{ Poverty-minimizing weights } \\
\cline { 2 - 9 } & Health & Education & $\begin{array}{c}\text { Standard } \\
\text { of living }\end{array}$ & p-value & Health & Education & $\begin{array}{c}\text { Standard } \\
\text { of living }\end{array}$ & p-value \\
\hline 0.10 & 0.30 & 0.20 & 0.50 & 0.033 & 0.30 & 0.50 & 0.20 & 0.053 \\
\hline 0.20 & 0.30 & 0.20 & 0.50 & 0.050 & 0.30 & 0.50 & 0.20 & 0.030 \\
\hline 0.30 & 0.20 & 0.30 & 0.50 & 0.053 & 0.40 & 0.40 & 0.20 & 0.037 \\
\hline 0.40 & 0.30 & 0.20 & 0.50 & 0.037 & 0.40 & 0.40 & 0.20 & 0.047 \\
\hline 0.50 & 0.30 & 0.20 & 0.50 & 0.023 & 0.50 & 0.25 & 0.25 & 0.017 \\
\hline 0.60 & 0.25 & 0.25 & 0.50 & 0.047 & 0.40 & 0.40 & 0.20 & 0.017 \\
\hline 0.70 & 0.25 & 0.25 & 0.50 & 0.030 & 0.50 & 0.30 & 0.20 & 0.050 \\
\hline 0.80 & 0.20 & 0.30 & 0.50 & 0.050 & 0.40 & 0.40 & 0.20 & 0.043 \\
\hline 0.90 & N/A & N/A & N/A & 0.247 & N/A & N/A & N/A & 0.240 \\
\hline
\end{tabular}

Notes: N/A suggests that there is no alternative dimensional weight allocation where the multidimensional poverty distribution with these weights offers more (or less) multidimensional poverty compared to the multidimensional poverty obtained with other admissible weights. 
To make our results operational, Table 3 presents the multidimensional poverty headcount ratio with the benchmark weights and the feasible range of multidimensional poverty headcount ratio with alternative weights ranging between upper and lower bounds of weights at different crossdimensional multidimensional cut-off values (i.e., the weighted sum of deprivation levels). For instance, if one sets cross-dimensional cut-off to $0.4,91.1 \%$ of the population is considered multidimensionally poor if the dimensions are weighted equally. On the other hand, our findings suggest that the multidimensional headcount ratio ranges between $59.0 \%$ and $97.6 \%, 65.0 \%$ and $97.6 \%, 72.3 \%$ and $96.0 \%$, when dimensional weights range between 0.1 and $0.8,0.15$ and $0.7,0.2$ and 0.5 , respectively. In other words, irrespective of the weight allocation to dimensions between 0.1 and 0.8, the multidimensional headcount ranges between 59.0\% and 97.6\%. Another way of interpreting the findings is that irrespective of dimensional weight variation between 0.1 and $0.8,0.15$ and $0.7,0.2$ and 0.5 , policymakers can be sure that the multidimensional headcount ratio in this population ranges between $59.0 \%$ and $97.6 \%, 65.0 \%$ and $97.6 \%, 72.3 \%$, and $96.0 \%$, respectively. Hence, they are aware of the multidimensional poverty range based on the upper and lower bound weights that they choose for poverty dimensions without the need to worry about the effect of weights on the multidimensional poverty outcomes. We interpreted the results based on the choice of the cross-dimensional cut-off value of 0.4 ; however, policymakers can also evaluate the variation in multidimensional headcount ratio at different levels of cross-dimensional cut-off values (see Table 3 for feasible ranges of multidimensional headcount ratio at different cross-dimensional cut-off values).

\begin{tabular}{|c|c|c|c|c|}
\hline $\begin{array}{c}\text { Table 3. Multidimensional poverty headcount ratio with the benchmark weights and the feasible range of } \\
\text { multidimensional poverty headcount ratio with alternative weights ranging between upper and lower bounds of weights }\end{array}$ \\
\hline $\begin{array}{c}\text { Cross- } \\
\text { dimensional } \\
\text { multidimensiona } \\
\text { 1 poverty cut-off } \\
\text { value }(k)\end{array}$ & $\begin{array}{c}\text { Benchmark } \\
\text { multidimensional } \\
\text { poverty headcount } \\
\text { ratio }(\%)\end{array}$ & $\begin{array}{c}\text { Feasible range of } \\
\text { multidimensional } \\
\text { poverty headcount ratio } \\
(\%) \text { when } \\
w^{L}=0.10 \& w^{U}=0.80\end{array}$ & $\begin{array}{c}\text { Feasible range of } \\
\text { multidimensional } \\
\text { poverty headcount ratio } \\
(\%) \text { when } \\
w^{L}=0.15 \& w^{U}=0.70\end{array}$ & $\begin{array}{c}\text { Feasible range of } \\
\text { multidimensional } \\
\text { poverty headcount ratio } \\
(\%) \text { when } \\
w^{L}=0.20 \& w^{U}=0.50\end{array}$ \\
\hline 0.10 & 99.5 & $93.0-100.0$ & $98.5-100.0$ & $99.0-99.8$ \\
\hline 0.20 & 99.0 & $66.0-99.5$ & $90.1-99.5$ & $94.5-99.5$ \\
\hline 0.30 & 96.9 & $66.0-99.5$ & $66.0-99.5$ & $92.0-99.0$ \\
\hline 0.40 & 91.1 & $59.0-97.6$ & $65.0-97.6$ & $72.3-96.0$ \\
\hline 0.50 & 87.6 & $58.5-95.6$ & $58.5-95.1$ & $58.5-90.2$ \\
\hline 0.60 & 70.3 & $17.2-93.5$ & $39.2-92.9$ & $39.2-86.2$ \\
\hline 0.70 & 39.1 & $14.8-92.4$ & $16.2-86.1$ & $39.1-66.1$ \\
\hline 0.80 & 37.7 & $9.6-82.0$ & $9.6-66.1$ & $9.6-38.8$ \\
\hline 0.90 & 9.6 & $8.9-37.1$ & $8.9-37.1$ & $9.6-9.6$ \\
\hline
\end{tabular}

A couple of interesting cases emerge while examining the results. Firstly, the feasible range of multidimensional poverty may be similar at different multidimensional poverty cut-off values when dimensions get different set of weights. For instance, if multidimensional poverty cut-off is set to 0.2 or 0.3 , multidimensional poverty headcount ratio ranges between $66.0 \%$ and $99.5 \%$ when dimensional 
weights are allowed to range between 0.1 and 0.8 . In other words, changing the weights of each dimension slightly (see panel A of Table 2 for the poverty-maximizing and -minimizing weights for the cases when $k$ is set to 0.2 and 0.3 ) results in the same range of multidimensional headcount ratio at higher cross-dimensional cut-off value. Secondly, the difference between the lowest and highest multidimensional levels in the feasible range of multidimensional poverty headcount ratio is relatively higher at higher cross-dimensional multidimensional poverty cut-off values when the dimensional weights are allowed to vary more. For instance, the ranges in the feasible range of multidimensional poverty headcount ratio are $77.6 \%, 69.9 \%$ and $27 \%$ when $k$ is set to 0.7 when dimensional weights vary between 0.1 and $0.8,0.15$ and $0.7,0.2$ and 0.5 , respectively. On the other hand, the ranges in feasible range of multidimensional poverty headcount ratio are relatively lower at the lower levels of multidimensional poverty cut-off values. To put it differently, this exercise suggests that policymakers should be concerned more about the effect of the weights on the multidimensional poverty outcomes at higher levels of multidimensional poverty cut-offs.

\subsection{Multidimensional poverty in Canada}

In the previous subsection, we obtained the poverty-maximizing and -minimizing weight allocations across the poverty dimensions that identified the highest and lowest numbers of individuals that are identified multidimensionally poor at different cross-dimensional cut-offs where we set the poverty aversion parameter to zero (i.e., $\alpha=0$ ). In this subsection, we examine the distribution of the depth of multidimensional poverty when we set the poverty aversion parameter above zero with the use of cardinal poverty indicators. To do this, we obtain data from the Canadian Survey of Labour and Income Dynamics that was carried out in 2006 about the Canadian population that is living in urban areas with a population below 29,999 with a household size of two where the sample consists of 4,418 individuals.

To measure the depth of multidimensional poverty, we use the achievements of these individuals in income and education, which are measured by after-tax income and years of schooling, respectively. Table 4 presents the deprivation cut-off values for each dimension, the percentage of deprived individuals in each indicator and percentages of multidimensional headcount ratio, poverty gap, and the severity of poverty, respectively (i.e. when $\alpha$ parameter is set to 0,1 , and 2 , respectively), where we consider individual to be multidimensionally poor if she/he is deprived at least in one dimension. We find that $12.2 \%$ of the population living in urban areas with a population below 29,999 with a household size of two is multidimensionally poor and that $5.3 \%$ and $7.3 \%$ of individuals are deprived in income and education dimensions, respectively. 


\begin{tabular}{|c|c|c|}
\hline $\begin{array}{l}\text { Table } 4 \\
\text { Multidimer } \\
\text { household }\end{array}$ & erty levels for Canadians living in urban areas that have a population be & 29,999 with a \\
\hline Dimension & Deprivation criteria & $\begin{array}{c}\text { \% of deprived } \\
\text { individuals }\end{array}$ \\
\hline Income & $\begin{array}{l}\text { An individual is considered to be deprived in income if that person } \\
\text { lives in a household that has income less than the Statistics Canada's } \\
\text { so-called low-income cut-off (LICO) for the individuals that are living } \\
\text { in urban areas with a population below } 29,999 \text { with a household size of } \\
\text { two, which is } \$ 16,008 \text {. }\end{array}$ & 5.3 \\
\hline Education & $\begin{array}{l}\text { An individual is deprived if she/he has not completed eight years of } \\
\text { schooling. }\end{array}$ & 7.3 \\
\hline Aggregate & sional poverty measures when income and education weighted equally & \\
\hline Multidimer & dcount ratio when $\alpha=0$ & 12.2 \\
\hline Multidimer & erty gap when $\alpha=1$ & 2.2 \\
\hline Multidimer & erty severity when $\alpha=2$ & 1.2 \\
\hline
\end{tabular}

The poverty measures presented in Table 4 are aggregate multidimensional poverty outcomes and do not make use of the empirical distribution of the depth of poverty. Aggregate poverty measures in Table 4 suggest that there are more deprived individuals in education than that of income $(7.3 \%$ vs. $5.3 \%$ ); however, shortfalls (i.e., normalized poverty gaps) in income may be higher than that of shortfalls in education. Hence, to understand the depth of poverty and the effect of weight allocation on the weighted normalized poverty gaps, we will examine the full empirical distribution of the weighted normalized poverty gaps among the multidimensionally poor.

Rather than relying on the average of weighted normalized poverty gaps, we compare the distribution of the equally weighted normalized poverty gaps (i.e., when $\boldsymbol{w}=(0.5,0.5))$ with the distribution of the weighted normalized poverty gaps obtained with alternative weights. In this application, we keep the parameters of $\boldsymbol{l}$ (i.e. dimension-specific deprivation cut-offs), $k$ (i.e., individual is considered poor if deprived in at least one dimension), $\alpha$ (i.e., $\alpha=1$ ) the same to examine the distribution of the weighted normalized poverty gaps (i.e., g levels) to obtain a weighting scheme for each indicator that gives the highest (lowest) number of individuals who experience a depth of poverty above a given level of weighted normalized poverty gap. As in the Kenyan case, we also impose three higher and lower bounds to the dimensional weights where dimensional weights range between 0.15 and $0.85,0.25$ and $0.75,0.35$ and 0.65 , respectively. 


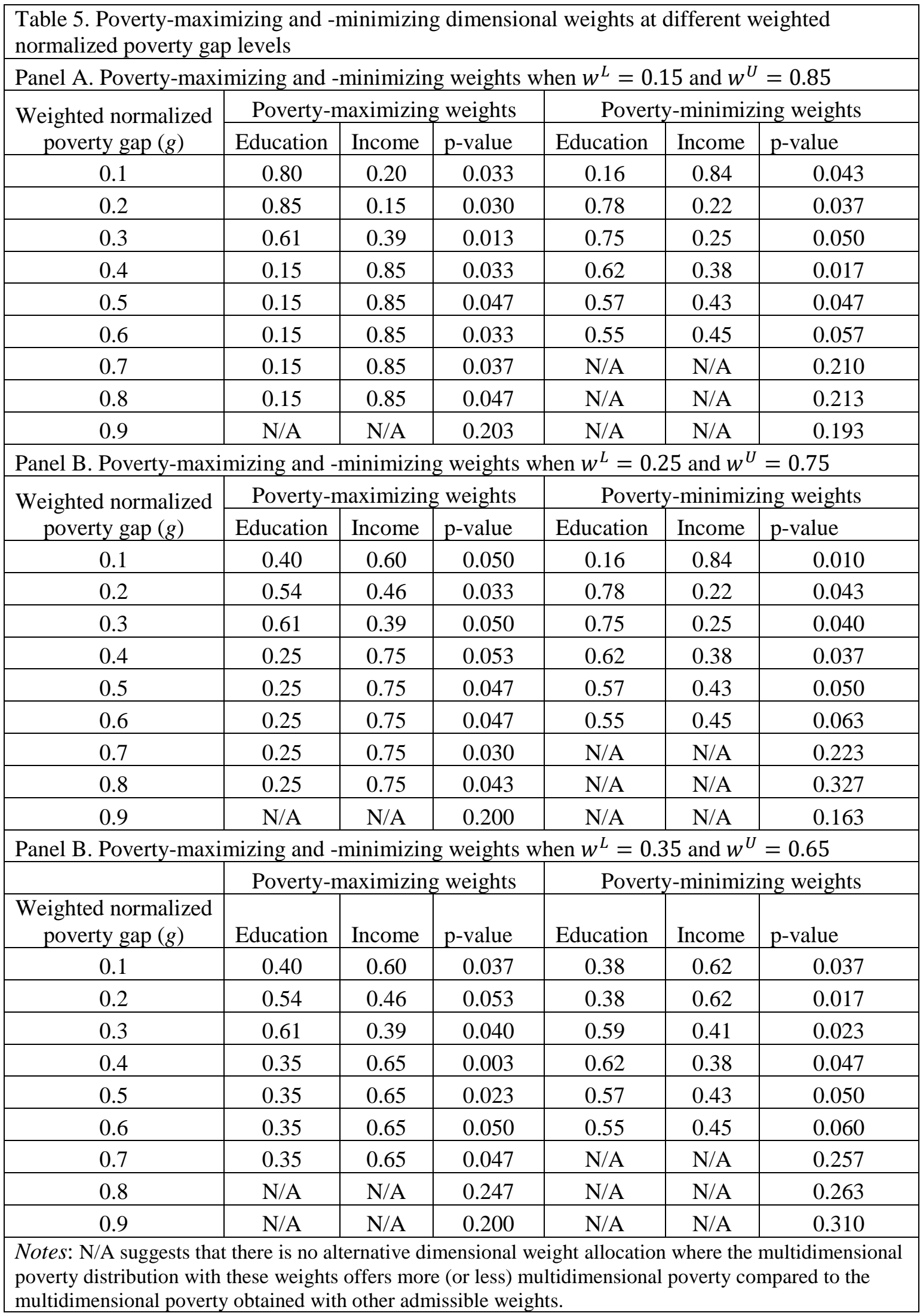

Panels A, B and C of Table 5 present the poverty-maximizing and -minimizing dimensional weights at different weighted normalized poverty gap levels that maximizes and minimizes the 
number of poor with a weighted normalized poverty gap above a given $g$ level when dimensional weights range between 0.15 and $0.85,0.25$ and $0.75,0.35$ and 0.65 , respectively ${ }^{10}$. Note that we use a different set of upper and lower dimensional weights in this application and that this table also reports the significance of poverty-maximizing and -minimizing weights at different weighted normalized poverty gaps obtained by using block size and replication numbers of 8 and 300, respectively. Overall, we find that there are always significant alternative dimensional weights that yield higher and lower percentages of individuals that have a normalized poverty gap above a given level of a normalized poverty gap of $g$ up to weighted normalized poverty gap of 0.6 irrespective of lower and upper bounds of weights. However, above the weighted normalized poverty gap of 0.6 , we also find that there are cases where there is no single set of admissible weights that offers a higher proportion of people with normalized poverty gaps above a given level. In other words, when $g=0.7, g=0.8$, and $g=0.9$, the percentages of people with normalized poverty gaps above these levels is the lowest irrespective of any admissible weights chosen between the upper and lower bounds of weights.

To make the results more apparent, Table 6 presents the weighted normalized poverty gap distribution with the benchmark weights and confidence intervals of the percentage of poor with normalized poverty gap above a given level with alternative weights ranging between upper and lower bounds of weights. For instance, $12.2 \%$ of the poor population experience weighted normalized poverty gaps equal to and above 0.4 when each dimension is weighted equally. However, when the dimensional weights are allowed a range between 0.15 and $0.85,0.25$ and $0.75,0.35$ and 0.65 , the percentage of poor that have weighted normalized poverty above 0.4 can range between 5.0 and 15.6, 5.0 and 14.8, and 5.0 and 13.7, respectively. The most interesting finding of this application is that when dimensional weights are allowed range between 0.15 and 0.85 , slightly different weighting allocations to income and education dimensions result in largely different poverty outcomes at lower levels of weighted normalized poverty gaps. For example, if education and income dimensions are weighted 0.85 and 0.15 respectively, $35.4 \%$ of the poor has weighted normalized poverty gaps above 0.2. However, if education and income dimensions are weighted 0.78 and 0.22 , respectively, $24.8 \%$ of the poor has weighted normalized poverty gaps above 0.2 . Similarly, when education and income dimensions get weights of 0.61 and 0.39 (0.75 and 0.25$), 12.6 \%$ (21.3\%) of the poor population has weighted normalized poverty gaps above 0.3 . The above scenarios clearly show that relatively close weight allocations to education and income dimensions result in two extreme ends of the percentage of population having weighted normalized poverty gaps above a given weighted normalized poverty gap. This finding is quite important for policymakers. Given that relatively close weight allocations to poverty dimensions can lead to two extreme distributions of weighted normalized poverty gaps,

\footnotetext{
${ }^{10}$ It should be noted that allocating different benchmark weights to poverty indicators will change the empirical distribution of the normalized poverty gaps for the population of the poor. However, a change in the empirical distribution of normalized poverty gaps with alternative benchmark weights does not alter our findings for the two extreme weighting schemes for given poverty thresholds as we consider all admissible weights to obtain these two extreme case weighting vectors.
} 
policymakers need to be careful with their choice of weights as two seemingly similar weight choices may lead to extremely different policy decisions. Hence, in practice, policymakers need to conduct some robustness analysis examining the effect of their normative decisions. Our methodology tackles this issue by deriving a feasible range of the percentage of multidimensionally poor that have weighted normalized poverty gap above a given threshold irrespective of any weight choice that ranges between upper and lower bounds.

\begin{tabular}{|c|c|c|c|c|}
\hline $\begin{array}{c}\text { Weighted } \\
\text { normalized } \\
\text { poverty gap }(g)\end{array}$ & $\begin{array}{l}\% \text { of poor with } \\
\text { normalized } \\
\text { poverty gaps } \\
\text { above } g \text { level }\end{array}$ & $\begin{array}{c}\text { Feasible range of } \% \text { of } \\
\text { poor with normalized } \\
\text { poverty gaps above } g \\
\text { level when } w^{L}=0.15 \& \\
w^{U}=0.85\end{array}$ & $\begin{array}{c}\text { Feasible range of } \% \text { of } \\
\text { poor with normalized } \\
\text { poverty gaps above } g \\
\text { level when } w^{L}=0.25 \& \\
w^{U}=0.75\end{array}$ & $\begin{array}{c}\text { Feasible range of } \% \text { of } \\
\text { poor with normalized } \\
\text { poverty gaps above } g \\
\text { level when } w^{L}=0.35 \& \\
w^{U}=0.65\end{array}$ \\
\hline 0.1 & 63.9 & $40.6-73.1$ & $46.9-66.3$ & $50.4-66.3$ \\
\hline 0.2 & 29.8 & $24.8-35.4$ & $25.0-34.3$ & $27.4-34.3$ \\
\hline 0.3 & 20.6 & $12.6-21.3$ & $12.6-21.3$ & $17.2-21.3$ \\
\hline 0.4 & 12.2 & $5.0-15.6$ & $5.0-14.8$ & $5.0-13.7$ \\
\hline 0.5 & 4.8 & $2.4-13.7$ & $2.4-11.5$ & $2.4-9.8$ \\
\hline 0.6 & 0.6 & $0.2-11.1$ & $0.2-8.7$ & $0.2-6.7$ \\
\hline 0.7 & 0.0 & $0.0-8.1$ & $0.0-5.9$ & $0.0-1.5$ \\
\hline 0.8 & 0.0 & $0.0-5.9$ & $0.0-0.4$ & $0.0-0.0$ \\
\hline 0.9 & 0.0 & $0.0-0.0$ & $0.0-0.0$ & $0.0-0.0$ \\
\hline
\end{tabular}

This exercise clearly shows the importance of weight allocation in assessing poverty in arriving at policy. Let us provide a hypothetical example to show how a small change in the weighting scheme across the poverty indicators can have major policy implications. In this example, the government would like to identify deprived individuals and provide support for them. However, there is a limit on how many individuals can be supported, and it is decided to do so only for individuals who have a weighted shortfall above 0.3 . The government might want to give more importance to the education over income (e.g., they might argue that improvements in education lead to higher economic returns) and they attach relative weights of $61 \%$ and $39 \%$ to education and income, respectively to identify the individuals that they plan to support. A week later (after careful considerations and discussions), the government decides to give even more importance to education over income with the weights now given to education and income are $75 \%$ and $25 \%$, respectively. The allocation of $61 \%$ or $75 \%$ weight towards education is likely to be perceived the same by the public since it would suggest that "policymakers allocate more importance to education" by giving more weight to education and increasing the weight of education does not alter the choice of individuals that would benefit from the support programme. However, we know from the results of the above example that the percentage of poor who experience weighted normalized poverty gaps above 0.3 is the highest when education and income indicators are given roughly $61 \%$ and $39 \%$ 
weights, respectively. On the other hand, if the relative importance given to education increases to $75 \%$, then the percentage of poor who are deprived above the weighted normalized poverty gap of 0.3 is the lowest. In the first case, $21.3 \%$ of the poor would have received such support; however after increasing the importance given to education, this percentage drops to 12.6. This hypothetical example clearly shows how a relatively small change in the weighting scheme might lead to dramatically different policy implications. Hence, obtaining a feasible range of the percentage of poor experiencing normalized poverty gap above a given level would provide a better understanding of multidimensional poverty distribution irrespective of the weight allocation to the dimensions that ranges between the upper and lower bounds.

\section{Conclusion}

Obtaining multidimensional poverty levels for a given population requires various normative calls. In this paper, we offer a methodology, which has a similar structure as the SD efficiency and super-efficiency methodologies to obtain dimensional weighting vectors for a given multidimensional poverty threshold that maximizes and minimizes the percentage of population that have multidimensional poverty above this threshold. This would allow policymakers to obtain a feasible range of multidimensional poverty above a given threshold, something that would be useful in assessing the sensitivity of the multidimensional poverty measures to alternative weight choices.

To illustrate the use of the methodology, we use microdata sets from Kenya and Canada, which enabled us to examine the multidimensional poverty distributions. With the Kenyan case, we obtain weighting schemes of poverty dimensions at different levels of cross-dimensional multidimensional poverty cut-offs (i.e., a threshold levels that determines who is multidimensionally poor), which would yield the highest and lowest percentage of the population that would be identified as multidimensionally poor. With the Canadian data, we examine the depth of multidimensional poverty by looking at the distribution of weighted normalized poverty gaps with the pre-determined weights and obtain weighting schemes of poverty indicators that lead to a higher (lower) percentage of poor experiencing a depth of poverty above a given normalized poverty gap.

These two-empirical applications enabled us to see that different weights allocated to poverty indicators that are different from pre-determined weights can produce extremely different multidimensional poverty outcomes for a given population and two relatively similar weighting schemes may produce extremely different multidimensional poverty outcomes.

In our analysis, we only considered multidimensional poverty at a given time (i.e., snapshot poverty). One can further extend the methodology proposed in this paper to assess lifetime poverty. Lifetime poverty of a household (or individual) is currently measured by obtaining the sum of weighted snapshot poverty levels in different time periods. Similar to the case of snapshot poverty, a different set of weights could be allocated to snapshot poverty levels at different time periods to 
examine the sensitivity of lifetime poverty based on weight allocation across different time periods. Similarly, in another possible application one can compare two populations to obtain which set of weight allocations lead to higher multidimensional poverty in a given population compared to another one. Depending on the results, one may either conclude that there is higher multidimensional poverty in a given population compared to another one irrespective of weight allocations to poverty dimensions or different weight allocations to poverty dimensions may offer two alternative scenarios where one population is multidimensionally poorer compared to other one or vice versa.

Finally, another future research direction is to extend the multidimensional poverty analysis to multidimensional inequality analysis by eliminating the indicator-specific deprivation cut-offs and analyse the full distribution of well-being indicators. In this case, one can obtain a combination of well-being indicators which would yield the highest (lowest) possible inequality for a given population at different parts of the empirical well-being distribution.

Acknowledgments. Mehmet Pinar would like to acknowledge the Research Investment Fund of Edge Hill University for their financial support. Thanasis Stengos would like to acknowledge financial support from the Natural Science and Engineering Research Council (NSERC) of Canada (401004).

\section{References}

Aaberge, R., \& Brandolini, A. (2015). Multidimensional poverty and inequality. In: A.B. Atkinson, \& F. Bourguignon (Eds.), Handbook of income distribution (pp. 141-216). Vol. 2, Amsterdam: Elsevier. Aaberge, R., Peluso, E., \& Sigstad, H. (2015). The dual approach for measuring multidimesional deprivation and poverty. Discussion papers 820, Statistics Norway, Research Department.

Agliardi, E., Pinar, M., \& Stengos, T. (2015). An environmental degradation index based on stochastic dominance. Empirical Economics, 48(1), 439-459.

Agrell, P.J., Stam, A., \& Fischer, G.W. (2004) Interactive multiobjective agro-ecological land use planning: The Bungoma region in Kenya. European Journal of Operational Research, 158, 194-217.

Alkire, S., \& Foster, J.E. (2011). Counting and multidimensional poverty. Journal of Public Economics, 95, 476-487.

Alkire, S., \& Santos, M.E. (2014). Measuring acute poverty in the developing world: robustness and scope of the multidimensional poverty index. World Development, 59, 251-274.

Alkire, S., Roche, J.M., Santos, M.E., \& Seth, S. (2011). Multidimensional poverty index 2011: brief methodological note. OPHI Briefing 07.

Allison, R.A., \& Foster, J.E. (2004). Measuring health inequality using qualitative data. Journal of Health Economics, 27, 505-524.

Anderson G (1996) Nonparametric tests of stochastic dominance in income distributions. Econometrica, 64, 1183-1193.

Anderson, G. \& Post, T. (2018). Increasing discriminatory power in well-being analysis using convex stochastic dominance. Social Choice and Welfare, 51,551-561. 
Anderson, G., Post, T. \& Whang, Y.-J. (2019) Somewhere between utopia and dystopia: choosing from multiple incomparable prospects. Journal of Business and Economic Statistics, forthcoming. doi: $\underline{10.1080 / 07350015.2018 .1515765}$

Arvanitis, S., Hallam, M. Post, T., \& Topaloglou, N. (2019). Stochastic Spanning. Journal of Business and Economics Statistics, forthcoming. doi: 10.1080/07350015.2017.1391099

Arvanitis, S., \& Topaloglou, N. (2017). Testing for prospect and Markowitz stochastic dominance efficiency. Journal of Econometrics, 198(2), 253-270.

Athanassoglou, S. (2016). Revisiting worst-case DEA for composite indicators. Social Indicators Research, 128, 1259-1272.

Atkinson, A.B. (1987). On the measurement of poverty. Econometrica, 55, 749-764.

Atkinson, A.B. (2003). Multidimensional deprivation. Contrasting social welfare and counting approaches. Journal of Economic Inequality, 1, 51-65.

Barrett, G.F., \& Donald, S.G. (2003). Consistent tests for stochastic dominance. Econometrica, 71, 71-104.

Bennett, C.J. (2010). Improving the power of multiple testing procedures via single-step methods. SSRN Working Paper No. 1654062.

Bennett, C.J. (2013). Inference for dominance relations. International Economic Review, 54, 13091328.

Bennett, C.J., \& Mitra, S. (2013). Multidimensional poverty: measurement, estimation and inference. Econometric Review, 32, 57-83.

Berenger, V. (2017). Using ordinal variables to measure multidimensional poverty in Egypt and Jordan. Journal of Economic Inequality, 15(2), 143-173.

Bokrantz, R., \& Fredriksson, A. (2017). Necessary and sufficient conditions for Pareto efficiency in robust multiobjective optimization. European Journal of Operational Research, 262, 682-692.

Bossert, W., Chakravarty, S.R., \& D'Ambrosio, C. (2013). Multidimensional poverty and material deprivation with discrete data. Review of Income Wealth, 59(1), 29-43.

Bossert, W., D'Ambrosio, C., \& Peragine, V. (2007). Deprivation and social exclusion. Economica, 74, 777-803.

Branda, M. (2015). Diversification-consistent data envelopment analysis based on directional-distance measures. Omega, 52, 66-75.

Branda, M., \& Kopa, M. (2016). Dea models equivalent to general n-th order stochastic dominance efficiency tests. Operations Research Letters, 44, 285-289.

Brauers, W.K.M. (2008). Multi-objective decision making by reference point theory for a well-being economy. Operational Research, 8, 89-104.

Bruni, R., Cesarone, F., Scozzari, A., \& Tardella, F. (2017). On exact and approximate stochastic dominance strategies for portfolio selection. European Journal of Operational Research, 259, 322- 
329.

Camargo Pérez, J., Carrillo, M.H., \& Montoya-Torres, J.R. (2015). Multi-criteria approaches for urban passenger transport systems: a literature review. Annals Operations Research, 226, 69-87.

Cambero, C., \& Sowlati, T. (2014) Assessment and optimization of forest biomass supply chains from economic, social and environmental perspectives - A review of literature. Renewable and Sustainable Energy Reviews, 36, 62-73.

Central Bureau of Statistics (CBS) [Kenya], Ministry of Health (MOH) [Kenya], ORC Macro (2004). Kenya Demographic and Health Survey 2003. Maryland.

Chakravarty, S.R., \& D'Ambrosio, C. (2006). The measurement of social exclusion. Review of Income and Wealth, 52, 377-398.

Chakravarty, S.R., \& Zoli, C. (2012). Stochastic dominance relations for integer variables. Journal of Economic Theory, 147(4), 1331-1341.

Chen, W., Gai, Y., \& Gupta, P. (2018). Efficiency evaluation of fuzzy portfolio in different risk measures via DEA. Annals of Operations Research, 269(1-2), 103-127.

Cherchye, L., Moesen, W., Rogge, N., \& Van Puyenbroeck, T. (2007). An introduction to 'benefit of the doubt' composite indicators. Social Indicators Research, 82(1), 111-145.

Cherchye, L., Moesen, W., Rogge, N., Van Puyenbroeck, T., Saisana, M., Saltelli, A., Liska, R., Tarantola, S. (2008). Creating composite indicators with DEA and robustness analysis: the case of the Technology Achievement Index. Journal of Operational Research Society, 59(2), 239-251

Cox, G. W., \& McCubbins, M. D. (1986). Electoral politics as a redistributive game. Journal of Politics, 48(2), 370-389.

Davidson, R., \& Duclos J.-Y. (2000). Statistical inference for stochastic dominance and for the measurement of poverty and inequality. Econometrica, 68, 1435-1464.

Diaz-Cayeros, A., Magaloni, B., \& Estévez, F. (2016). The political logic of poverty relief: Electoral strategies and social policy in Mexico. Cambridge: Cambridge University Press.

Dixit, A., \& Londregan, J. (1996). The determinants of success of special interests in redistributive politics. Journal of Politics, 58(4), 1132-1155.

Duclos, J.-Y., Makdissi, P., \& Wodon, Q. (2005). Poverty-dominant program reforms: the role of targeting and allocation rules. Journal of Development Economics, 77, 53-73.

Duclos, J.-Y., Makdissi, P., \& Wodon, Q. (2008). Socially improving tax reforms. International Economic Review, 49, 1505-1537.

Duclos, J.-Y., Sahn, D.E., \& Younger, S.D. (2006a). Robust multidimensional spatial poverty comparisons in Ghana, Madagascar, and Uganda. World Bank Economic Review, 20, 91-113. 
Duclos, J.-Y., Sahn, D.E., \& Younger, S.D. (2006b). Robust multidimensional poverty comparisons. Economic Journal, 116(514), 943-968.

Duclos, J.-Y., Sahn, D.E., \& Younger, S.D. (2011). Partial multidimensional inequality orderings. Journal of Public Economics, 95(3-4), 225-238.

Ehrgott, M., Ide, J., \& Schöbel, A. (2014). Minmax robustness for multi-objective optimization problems. European Journal of Operational Research, 239(1), 17-31.

Fakhar, M., Mahyarinia, M.R., \& Zafarini, J. (2018). On nonsmooth robust multiobjective optimization under generalized convexity with applications to portfolio optimization. European Journal of Operational Research, 265, 39-48.

Fang, Y., \& Post, T. (2016). Higher-degree stochastic dominance optimality and efficiency. European Journal of Operational Research, 261(3), 984-993.

Ferre, C., Ferreira, F.H.G., \& Lanjouw, P. (2012). Is there a metropolitan bias? The relationship between poverty and city size in a selection of developing countries. World Bank Economic Review, $26,351-382$.

Fliege J., \& Werner, R. (2013) Robust multiobjective optimization \& applications in portfolio optimization. European Journal of Operational Research, 234(2), 422-433.

Foster, J.E., Greer, J., \& Thorbecke, E. (1984). A class of decomposable poverty measures. Econometrica, 52, 761-776.

Foster, J.E., Greer, J., \& Thorbecke, E. (2010). The Foster-Greer-Thorbecke (FGT) poverty measures: 25 years later. Journal of Economic Inequality, 8(4), 491-524.

Foster, J.E., McGillivray, M., \& Seth, S. (2013). Composite indices: Rank robustness, statistical association, and redundancy. Econometric Review, 32(1), 35-56.

Foster, J.E., \& Shorrocks, A.F. (1998). Poverty orderings and welfare dominance. Social Choice and Welfare, 5, 179-198.

Goerigk, M., \& Schöbel, A. (2016). Algorithm engineering in robust optimization. In L. Kliemann, \& P. Sanders (Eds.), Algorithm engineering: Selected results and surveys. In LNCS State of the Art: vol. 9220. Springer http://arxiv.org/abs/1505.04901. Final Volume for DFG Priority Program 1307.

Golden, M., \& Min, B. (2013). Distributive politics around the world. Annual Review of Political Science, 16(12), 1-27.

Gonzalo, J., \& Olmo, J. (2014). Conditional stochastic dominance tests in dynamic settings. International Economic Review, 55, 819-838.

Ide, J., \& Schöbel, A. (2016). Robustness for uncertain multi-objective optimization: a survey and analysis of different concepts. OR Spectrum, 38, 235-271.

Kuosmanen, T. (2004). Efficient diversification according to stochastic dominance criteria. 
Management Science, 50, 1390-1406.

Kuosmanen, T., \& Post, T. (2001). Measuring economic efficiency with incomplete price information: With an application to European commercial banks. European Journal of Operational Research, 134(1), 43-58.

Lamb, J.D., \& Tee K.-H. (2012). Data envelopment analysis models of investment funds. European Journal of Operational Research, 216(3), 687-696.

Leshno, M., \& Levy, H. (2002). Preferred by “all” and preferred by "most" decision makers: Almost stochastic dominance. Management Science, 48(8), 1074-1085.

Lim, S., Oh, K., \& Zhu, J. (2014). Use of DEA cross-efficiency evaluation in portfolio selection: An application to Korean stock market. European Journal of Operational Research, 236, 361-368.

Linton, O., Maasoumi, E., \& Whang, Y.-J. (2005). Consistent testing for stochastic dominance under general sampling schemes. Review of Economic Studies, 72, 735-765.

Linton O.B., Post T., \& Whang Y.-J. (2014). Testing for the stochastic dominance efficiency of a given portfolio, Econometrics Journal, 17, 59-74.

Livert, F., \& Gainza, X. (2018). Distributive politics and spatial equity: The allocation of public investment in Chile. Regional Studies, 52(3), 403-415.

Lizyayev, A., \& Ruszczynski, A. (2012). Tractable almost stochastic dominance. European Journal of Operational Research, 218, 448-455.

Luca, D., \& Rodríguez-Pose, A. (2015). Distributive politics and regional development: Assessing the territorial distribution of Turkey's public investment. Journal of Development Studies, 51 (11), 15181540.

Maasoumi, E., (1986). The measurement and decomposition of multi-dimensional inequality.

Econometrica, 54, 991-997.

Maasoumi, E., \& Racine, J.S. (2016). A solution to aggregation and an application to multidimensional well-being frontiers. Journal of Econometrics, 191, 374-383.

Mehdi, T. (2019). Stochastic dominance approach to OECD's better life index. Social Indicators Research, 143(3), 917-954.

Ogwang, T., \& Abdou, A. (2003). The choice of principal variables for computing some measures of human well-being. Social Indicators Research, 64(1), 139-152.

Omrani, H., Alizadeh, A., \& Amini, M. (2019). A new approach based on BWM and MULTIMOORA methods for calculating semi-human development index: An application for provinces of Iran. Socio-Economic Planning Sciences forthcoming. doi: 10.1016/j.seps.2019.02.004

Palma, C.D., \& Nelson, J.D. (2010). Bi-objective multi-period planning with uncertain weights: A robust optimization approach. European Journal of Forest Research, 129(6), 1081-1091.

Pinar, M., Stengos, T., \& Topaloglou, N. (2013). Measuring human development: a stochastic 
dominance approach. Journal of Economic Growth, 18, 69-108.

Pinar, M., Stengos, T., \& Topaloglou, N. (2017). Testing for the implicit weights of the dimensions of the Human Development Index using stochastic dominance. Economics Letters, 161, 38-42.

Pinar, M., Stengos, T., \& Yazgan, M.E. (2015). Measuring human development in the MENA region. Emerging Markets Finance and Trade, 51(6), 1179-1192

Post, T. (2003). Empirical tests for stochastic dominance efficiency. Journal of Finance, 58, 19051932.

Post, T., \& Kopa, M. (2013). General linear formulations of stochastic dominance criteria. European Journal of Operational Research, 230, 321-332.

Post, T., \& Poli, V. (2016). Portfolio analysis using stochastic dominance, relative entropy, and empirical likelihood. Management Science, 63(1), 153-165.

Rodríguez-Pose, A., Psycharis, Y., \& Tselios, V. (2016). Politics and Investment: Examining the Territorial Allocation of Public Investment in Greece. Regional Studies, 50(7), 1097-1112.

Scaillet, O., \& Topaloglou, N. (2010). Testing for stochastic dominance efficiency. Journal of Business and Economic Statistics, 28, 169-180.

Sethanan, K., \& Neungmatcha, W. (2016). Multi-objective particle swarm optimization for mechanical harvester route planning of sugarcane field operations. European Journal of Operational Research, 252, 969-984.

Shorrocks, A.F., \& Foster, J.E. (1987). Transfer sensitive inequality measures. Review of Economic Studies, 54(3), 485-497.

Silva, D., \& Nakata, T. (2009). Multi-objective assessment of rural electrification in remote areas with poverty considerations. Energy Policy, 37, 3096-3108.

Singh, R.K., Murty, H.R., Gupta, S.K., \& Dikshit, A.K., 2012. An overview of sustainability assessment methodologies. Ecological Indicators, 15(1), 281-299.

Smits, J., \& Steendijk, R. (2015). The international wealth index (IWI). Social Indicators Research, 122(1), 65-85.

Soyster A. (1973) Convex programming with set-inclusive constraints and applications to inexact linear programming. Operations Research, 21(5), 1154-1157.

Tofallis, C. (2013). An automatic-democratic approach to weight setting for the new human development index. Journal of Population Economics, 26(4), 1325-1345.

Tofallis, C. (2014). On constructing a composite indicator with multiplicative aggregation and the avoidance of zero weights in DEA. Journal of the Operational Research Society, 65(5), 791-792. Toloo, M., Sohrabi, B., \& Nalchigar, S. (2009). A new method for ranking discovered rules from data mining by DEA. Expert Systems with Applications, 36(4), 8503-8508. 
Tone, K., \& Tsutsui, M. (2010). An epsilon-based measure of efficiency in DEA - A third pole of technical efficiency. European Journal of Operational Research, 207(3), 1554-1563.

Seth, S., \& McGillivray, M. (2018). Composite indices, alternative weights, and comparison robustness. Social Choice and Welfare, 51(4), 657-679.

Van de gaer, D., Vandenbossche, J., \& Figueroa, J.L. (2014). Children's health opportunities and project evaluation: Mexico's Oportunidades Program. World Bank Economic Review, 28, 282-310. Van Puyenbroeck, T., \& Rogge, N. (2017). Geometric mean quantity index numbers with Benefit-ofthe-Doubt weights. European Journal of Operational Research, 256(3), 1004-1014.

Verbunt, P., \& Rogge, N. (2018). Geometric composite indicators with compromise Benefit-of-theDoubt weights. European Journal of Operational Research, 264(1), 388-401.

Xidonas, P., Mavrotas, G., Hassapis, C., \& Zopounidis, C. (2017). Robust multiobjective portfolio optimization: A minimax regret approach. European Journal of Operations Research, 262(1), 299305.

Yalonetzky, G. (2013). Stochastic dominance with ordinal variables: conditions and a test. Econometric Review, 32(1), 126-163.

Yalonetzky, G. (2014). Conditions for the most robust multidimensional poverty comparisons using counting measures and ordinal variables. Social Choice and Welfare, 43(4), 773-807 